\title{
Potensi Bahaya Kerja Pada Pekerja Industri Manufaktur Logam
}

\section{Potential Work Hazard on Metal Manufacturing Industry}

\author{
Erna Agustin Sukmandari*, Tangguh Dwi Pramono*, Agung Tyas Subekti* \\ *Program Studi Keselamatan dan Kesehatan Kerja, \\ STIKES Bhakti Mandala Husada Slawi, Kabupaten Tegal, \\ Email : ernaagustin@stikesbhamadaslawi.ac.id.
}

\begin{abstract}
ABSTRAK
Upaya yang paling mendasar dalam penerapan sistem manajemen keselamatan dan kesehatan kerja pada perusahaan adalah melakukan identifikasi potensi bahaya agar dapat segera dilakukan upaya pengendaliannya. Penelitian ini merupakan penelitian kualitatif dengan teknik purposive sampling dalam penentuan sampelnya. Data dikumpulkan melalui wawancara mendalam dengan informan utama maupun informan pendukung. Keabsahan data dengan metode triangulasi sumber dan member checking. Berdasarkan hasil penelitian, terdapat lima jenis potensi bahaya pada pekerja manufaktur logam, yaitu bahaya asap, bahaya sinar, unsafe act, bahaya benda jatuh, dan bahaya serbuk besi. Asap hasil pengelasan dapat menyebabkan asfiksia dan manganisme. Sinar hasil pengelasan menyebabkan katarak dan kanker kulit. Unsafe act merupakan 88\% penyebab kecelakaan kerja. Cedera yang paling umum dialami pekerja saat tertimpa benda yang jatuh adalah memar, patah tulang, strain, dan terkilir. Debu logam bukan hanya dapat menyebabkan pneumoconiosis saja, namun pada paparan yang tinggi dapat pula menyebabkan penyakit kanker, asma, allergic alveolitis, dan iritasi.
\end{abstract}

Kata Kunci : Identifikasi Bahaya, Manufaktur Logam, Unsafe Act, Debu Logam, Keselamatan Dan Kesehatan Kerja

\begin{abstract}
The most fundamental effort in the implementation of occupational safety and health management systems in companies is to identify potential hazards so that control efforts can be made immediately. This research is a qualitative research with purposive sampling technique in determining the sample. Data was collected through in-depth interviews with key informants and supporting informants. Data validity with source triangulation method and member checking. Based on the results of the study, there are five types of potential hazards for metal manufacturing workers, namely the danger of smoke, the danger of light, unsafe act, the danger of falling objects, and the danger of iron powder. Welding smoke can cause asphyxia and manganism. The beam of the welding results causes cataracts and skin cancer. Unsafe acts are $88 \%$ of the causes of workplace accidents. The most common injuries experienced by workers when hit by falling objects are bruises, broken bones, strains, and sprains. Metal dust can not only cause pneumoconiosis, but high exposure can also cause cancer, asthma, allergic alveolitis, and irritation.
\end{abstract}

Keywords: Hazard Identification, Metal Manufacturing, Unsafe Act, Metal Dust, Occupational Health And Safety 


\section{PENDAHULUAN}

Industri logam merupakan industri hulu yang menjadi salah satu prioritas pemerintah seperti tertuang dalam Rencana Induk Pengembangan Industri Nasional. Industri hulu merupakan kelompok industri yang memproduksi bahan baku yang nantinya akan digunakan dalam proses produksi pada kelompok industri hilir. Jadi, peran industri hulu dalam produktivitasnya sangat berpengaruh terhadap produktivitas industri hilir (Kementerian Perindustrian, 2015).

Tercapainya produktivitas kerja yang optimal dilakukan dengan penerapan sistem manajemen keselamatan dan kesehatan kerja. Bagian dari sistem manejemen keselamatan dan kesehatan kerja yang paling mendasar adalah identifikasi terhadap bahaya kerja untuk selanjutnya dilakukan penilaian terhadap bahaya tersebut serta dilakukan upaya pengendalian/kontrol bahaya. Upaya pengendalian bahaya penting dilakukan dalam rangka meminimalisir terjadinya kelelahan, sakit, cedera, atau bahkan kecelakaan kerja, dimana kecelakaan kerja tersebut bisa berdampak fatal sampai menghilangkan nyawa pekerja. Oleh karena itu, penting sekali melakukan identifikasi potensi bahaya kerja agar dapat segera dilakukan upaya pengendaliannya.

Penelitian ini bertujuan untuk mengidentifikasi potensi bahaya pada pekerja industri manufaktur logam. Penelitian dilakukan dengan menggunakan metode penelitian kualitatif karena penelitian sejenis melalui metode kualitatif masih terbatas, sehingga penelitian ini dapat memperkaya ilmu pengetahuan yang ada.

\section{METODE}

Penelitian dilakukan pada salah satu industri manufaktur logam di Kabupaten Tegal yang menjadi mitra salah satu perusahaan alat berat nasional. Pengambilan data dilakukan pada bulan Februari s.d. Mei 2018. Penelitian ini merupakan penelitian kualitatif, dimana populasi dalam penelitian ini merupakan seluruh pekerja pada industri manufaktur logam tersebut. Informan penelitian diambil berdasarkan teknik purposive sampling sehingga didapatkan informan dalam penelitian ini sebanyak lima orang dengan total informan utama sebanyak 
empat orang, yang terdiri dari dua orang pekerja pada bagian welding, seorang pekerja bagian grinding, dan seorang pekerja bagian drilling. Adapun sebagai informan pendukung dalam penelitian ini adalah bagian manajemen sebanyak satu orang. Pengumpulan data dilakukan melalui wawancara mendalam dengan para informan. Wawancara mendalam dilakukan berdasarkan pedoman wawancara yang telah dibuat sebelum wawancara dilakukan, dimana topik dari pedoman wawancara tersebut dibuat sama antara informan utama maupun informan pendukung. Saat wawancara berlangsung, hasil wawancara didokumentasikan menggunakan alat perekam suara.

Data yang terkumpul diubah terlebih dahulu ke dalam bentuk transkripsi data, untuk kemudian dilakukan analisa data menggunakan Open Code 4.03. Data dianalisis dengan teknik analisa data interaktif yang meliputi data reduction, data display, dan conclusion drawing/verification. Keabsahan data dilakukan melalui triangulasi sumber dan member checking. Triangulasi sumber sebagai keabsahan data dalam penelitian ini dilakukan dengan mengambil data melalui berbagai sumber, yakni melalui informan utama maupun informan pendukung, sedangkan member checking dilakukan dengan proses wawancara mendalam yang dilakukan lebih dari sekali agar informan dapat memberikan feedback mengenai informasi yang telah diberikan sebelumnya dan mengurangi bias persepsi dari peneliti.

\section{HASIL}

Informan utama dalam penelitian ini memiliki masa kerja paling lama 10 tahun dan paling sedikit selama 1 tahun. Sedangkan untuk informan pendukung memiliki masa kerja 25 tahun. Adapun informasi lebih lengkap mengenai informan dalam penelitian ini dapat dilihat pada Tabel 1.

\section{Tabel 1. Karakteristik Informan Penelitian}

\begin{tabular}{ccclll}
\hline $\begin{array}{c}\text { Urutan } \\
\text { Informan }\end{array}$ & $\begin{array}{c}\text { Usia } \\
\text { (tahun) }\end{array}$ & $\begin{array}{c}\text { Jenis } \\
\text { Kelamin }\end{array}$ & Pendidikan & Bagian & $\begin{array}{c}\text { Masa Kerja } \\
\text { (tahun) }\end{array}$ \\
\hline Informan 1 & 40 & Laki-laki & SMP & Welding & 10 \\
Informan 2 & 40 & Laki-laki & SMA & Welding & 7 \\
Informan 3 & 31 & Laki-laki & SMK & Grinding & 1 \\
Informan 4 & 25 & Laki-laki & SMK & Drilling & 4 \\
Informan 5 & 40 & Laki-laki & SMA & Management & 25 \\
\hline
\end{tabular}


Tabel 2. Potensi Bahaya pada Industri Manufaktur Logam

\begin{tabular}{|c|c|c|c|}
\hline No. & Potensi Bahaya & Pengetahuan informan & Ungkapan informan \\
\hline 1. & Bahaya asap & $\begin{array}{l}\text { Menurut informan, potensi } \\
\text { bahaya asap merupakan } \\
\text { potensi bahaya bagi pekerja } \\
\text { terutama pada saat } \\
\text { melakukan pengelasan } \\
\text { dengan benda kerja yang } \\
\text { berukuran agak besar. }\end{array}$ & $\begin{array}{l}\text { “...yang keluar dariii asap, } \\
\text { sinaar, asap juga.. itu kan } \\
\text { pasti.” (Informan 1). } \\
\text { “....sama asap. Bahkan kan } \\
\text { kaloo lama, nggak, welding } \\
\text { yang agak gede...(Informan 2) }\end{array}$ \\
\hline 2. & Bahaya sinar & $\begin{array}{l}\text { Menurut informan, potensi } \\
\text { bahaya sinar dari mesin } \\
\text { pengelasan } \\
\text { berpengaruh terhadap para } \\
\text { pekerja. }\end{array}$ & $\begin{array}{l}\text { "Efeknya banyak yang } \\
\text { mesinnya kan juga sinar, dari } \\
\text { sinar." (Informan } 1 \text { ) }\end{array}$ \\
\hline 3. & Unsafe act & $\begin{array}{l}\text { Menurut informan, ada } \\
\text { kalanya pekerja dalam } \\
\text { keadaan lelah ataupun } \\
\text { pekerja yang masih baru } \\
\text { belajar menggunakan las } \\
\text { berpotensi menimbulkan } \\
\text { bahaya lainnya yang berasal } \\
\text { dari human error. }\end{array}$ & $\begin{array}{l}\text { “Itu pastine (pastinya) kalo } \\
\text { operatore (operatornya) lengah } \\
\text { apa capek...(Informan 1) } \\
\text { “Iya pokoknya kalo ada, ada } \\
\text { kaya orang belajar itu, apa, } \\
\text { nyala welding... se-seb- } \\
\text { sebelum nyala itu kan harus di } \\
\text { tutup..(Informan 2) }\end{array}$ \\
\hline 4. & $\begin{array}{l}\text { Bahaya benda } \\
\text { jatuh }\end{array}$ & $\begin{array}{l}\text { Menurut informan, pekerja } \\
\text { terancam terkena jatuhnya } \\
\text { benda kerja. }\end{array}$ & $\begin{array}{l}\text { "Ya.... itu tertimpa barang } \\
\text { jatuh" (Informan 3) }\end{array}$ \\
\hline 5. & $\begin{array}{l}\text { Bahaya serbuk } \\
\text { besi }\end{array}$ & $\begin{array}{l}\text { Menurut informan, debu } \\
\text { besi/serbuk besi yang } \\
\text { dihasilkan pada proses } \\
\text { grinding juga menyebar ke } \\
\text { divisi lain karena arah } \\
\text { angin, sehingga bahaya } \\
\text { debu bukan hanya } \\
\text { mengancam pekerja bagian } \\
\text { grinding saja tetapi juga } \\
\text { menjadi ancaman seluruh } \\
\text { pekerja. }\end{array}$ & $\begin{array}{l}\text { “Kan kadang grinding, kan } \\
\text { grinda kan... itu nya kesana } \\
\text { debunya”(debu menyebar ke } \\
\text { divisi lain) (Informan 3) }\end{array}$ \\
\hline
\end{tabular}

Berdasarkan hasil penelitian terdapat lima jenis potensi bahaya pada pekerja manufaktur logam, yaitu bahaya asap, bahaya sinar, unsafe act, bahaya benda jatuh, dan bahaya serbuk besi Informasi lebih lengkap bisa dilihat pada Tabel 2. 
Erna Agustin Sukmandari, Tangguh Dwi Pramono, Agung Tyas Subekti : Potensi Bahaya Kerja Pada ...

\section{PEMBAHASAN}

Asap merupakan salah satu potensi bahaya yang diungkapkan oleh informan pada penelitian ini. Proses pengelasan menghasilkan asap dan gas yang berbahaya. Beberapa jenis gas yang terdapat pada asap pengelasan seperti karbon monoksida (CO), ozon $\left(\mathrm{O}_{3}\right)$ nitric oksida, nitrogen dioksida, hidrogen florida, dan karbondioksida. Efek kesehatan dari asap yang dihasilkan oleh pengelasan antara lain kerusakan pada ginjal dan sistem saraf, sedangkan gas seperti karbon monoksida dapat menyebabkan bahaya asfiksia yang serius (Occupational Safety and Health Administration, 2014).

Selain gas tersebut, ternyata dalam asap pengelasan juga mengandung mangan, walaupun persentase mangan yang terdapat pada asap tersebut masih sedikit. Mangan yang terhirup dapat terakumulasi dan merusak paru-paru, hati, ginjal dan sistem saraf pusat. Adanya paparan mangan tersebut juga berdampak pada kesuburan para pekerja pria, dan pada penelitian ini semua informan berjenis kelamin laki-laki sehingga seluruh informan juga berisiko mengalami gangguan kesuburan. Selain itu, paparan yang terlalu lama terhadap konsentrasi mangan yang tinggi (> $1 \mathrm{mg} / \mathrm{m} 3$ ) di udara dapat menyebabkan sindrom Parkinsonian yang dikenal sebagai "manganisme" (The National Institute for Occupational Safety and Health, 2013).

Sinar atau cahaya juga merupakan salah satu potensi bahaya yang diugkapkan oleh informan penelitian. Cahaya yang dihasilkan pada proses pengelasan sangatlah terang dan dapat melampaui kemampuan iris mata dalam mengatur cahaya yang masuk ke mata dengan sangat cepat, sehingga mata akan terasa silau dan mata akan terasa sangat lelah. Pengelasan menghasilkan sinar ultraviolet dan sinar inframerah, dimana paparan jangka panjang terhadap sinar ultraviolet dan sinar inframerah dapat menimbulkan risiko katarak pada beberapa orang. Sedangkan sinar ultraviolet dapat menyebabkan kanker kulit pada jangka waktu yang lama (Thompson Rivers University, 2014).

Selain itu, ternyata paparan sinar ultraviolet dan sinar inframerah pada mata dapat menyebabkan 'arc eye' atau 'welder flash' yang merupakan peradangan pada kornea mata. Sebenarnya, kornea dapat memperbaiki dirinya 
sendiri dalam waktu satu sampai dua hari, namun, apabila kornea mata mengalami infeksi bisa mengakibatkan kebutaan (Safe Work Australia, 2012).

Menurut Heinrich, perilaku tidak aman pekerja atau unsafe act berperan sebesar 88\% terhadap terjadinya kecelakaan, sedangkan kondisi mekanis atau fisik yang tidak aman berperan sebesar 10\% dan hanya 2\% kondisi yang tidak dapat dicegah terjadinya kecelakaan. Menurut Heinrich, perilaku tidak aman merupakan akar permasalahan kecelakaan yang terjadi dan harus dilakukan pengendalian terhadapnya.

Hasil penelitian ini juga mengungkapkan bahwa unsafe act merupakan salah satu potensi bahaya pada pekerja (Manuele, 2011). Pentingnya dalam pengendalian perilaku tidak aman pada pekerja dapat dilakukan melalui beberapa pendekatan diantaranya adalah melalui pengawasan, hukuman, bimbingan, pelatihan, dan lain-lain. Adapun pendekatan yang terbaru dalam masaah tersebut adalah melalui pendekatan Behaviour Based Safety (BBS), yang sering digambarkan sebagai pendekatan bottom-up dan dengan dukungan top-down dari para pemimpin keselamatan kerja (Health and Safety Authority, 2013).

Benda kerja berpotensi untuk terjatuh atau mengenai pekerja. Benda jatuh bukan hanya benda yang jatuh dari atas kea rah bawah saja, namun peralatan, material, puing-puing yang dapat jatuh atau terlepas ke samping atau ke atas juga termasuk ke dalam kategori benda jatuh (Safe Work Australia, 2012). Benda jatuh dapat mengakibatkan cedera pada pekerja. Cedera yang paling umum dialami pekerja saat tertimpa benda yang jatuh adalah memar, patah tulang, strain, dan terkilir. Benda jatuh merupakan salah satu potensi bahaya di tempat kerja seperti yang disampaikan oleh informan pada penelitian ini.

Serbuk besi yang terdapat pada tempat penelitian ini berbentuk bubuk sehingga berpotensi untuk menghasilkan debu. Debu logam yang berada di tempat kerja perlu mendapatkan perhatian khusus karena bisa menimbulkan berbagai penyakit seperti pneumoconiosis. Selain itu, paparan yang tinggi terhadap debu juga dapat menyebabkan penyakit kanker, asma, allergic alveolitis, dan iritasi (WHO). Perubahan yang ditimbulkan pada paru-paru terhadap keberadaan debu tersebut juga sangat bervariasi. Paparan debu silika dapat menghasilkan semacam 
“pulau-pulau” jaringan parut yang dikelilingi oleh jaringan paru-paru normal. Daerah yang mengalami luka dipisahkan satu dengan yang lainnya oleh jaringan normal, sehingga elastisitas paru-paru masih terjaga. Akan tetapi berbeda halnya jika paru-paru tersebut terpapar oleh debu asbes, berilium, dan kobalt. Jaringan yang mengalami luka akan benar-benar menutupi permukaan saluran udara pada bagian dalam, sehingga paru-paru menjadi kaku dan kehilangan elastisitasnya. Akan tetapi tidak semua partikel yang dihirup menghasilkan jaringan parut. Debu besi dan debu karbon tetap berada di dalam makrofag hingga mereka dapat dibersihkan oleh paru-paru. Apabila fungsi makrofag dikalahan oleh partikel, maka partikel debu melapisi bagian dalam saluran udara tanpa menghasilkan jaringan parut, tetapi hanya menghasilkan kerusakan ringan atau tidak sama sekali (Canadian Centre for Occupational Health and Safety, 2018).

\section{SIMPULAN}

Berdasarkan hasil penelitian terdapat lima jenis potensi bahaya pada pekerja manufaktur logam, yaitu bahaya asap, bahaya sinar, unsafe act, bahaya benda jatuh, dan bahaya serbuk besi. Perlu dilakukan penelitian lanjutan menggunakan metode kuantitatif untuk dapat mengetahui seberapa besar pengaruh potensi bahaya tersebut terhadap para pekerja industri manufaktur logam.

\section{UCAPAN TERIMA KASIH}

Ucapan terima kasih kepada DRPM Kemenristekdikti melalui hibah Penelitian Dosen Pemula (PDP) tahun 2018, sehingga penelitian ini dapat terlaksana dan dapat berjalan dengan baik.

\section{DAFTAR PUSTAKA}

Canadian Centre for Occupational Health and Safety. 2018. What are the Effects of Dust on the Lung [Online]. Available from: $<$ https://www.ccohs.ca/oshanswers/chemicals/lungs_dust.html $>$ [Accesed 15 October 2018].

Health and Safety Authority. 2013. Behaviour_based_safety_guide[Online]. Available 


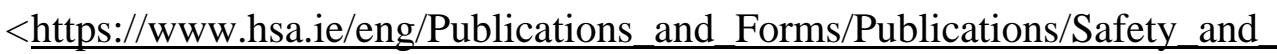
Health_Management/behaviour_based_safety_guide.pdf $>$ [Accesed 25 August 2018].

Kementerian Perindustrian. 2015. Rencana Induk Pembangunan Industri Nasional 2015-2035. Pusat Komunikasi Publik Kementerian Perindustrian Tahun 2015. [Online]. Available from: <http:// www. kemenperin. go.id/ ripin.pdf> [Accesed 24 Januari 2017].

Manuele, F.A. 2011. Reviewing Heinrich Dislodging Two Myths From the Practice of Safety[Online]. Available from: $<$ http://www.coshnetwork.org/sites/default/files/Reviewing\%20Heinrich\%2 0(Manuele\%20PS\%2010-2011).pdf $>$ [Accesed 26 September 2018].

Occupational Safety and Health Administration(b). 2014. Controlling Hazardous Fume and Gases during Welding [Online]. Available from: <https://www.osha.gov/Publications/OSHA_FS-3647_Welding.pdf> [Accesed 26 September 2018].

Safe Work Australia. 2012. Falling Objects Fact Sheet[Online]. Available from: $<$ https://www.safeworkaustralia.gov.au/system/files/documents/1702/falling _objects_fact_sheet.pdf $>$ [Accesed 26 September 2018].

The National Institute for Occupational Safety and Health.2013.Welding and Manganese [Online]. Available from: $<$ https://www.cdc.gov/niosh/topics/welding/default.html $>$ [Accesed 26 September 2018].

Thompson Rivers University. 2014. Welding safety Procedures[Online]. Available from: $<$ https://www.tru.ca/_shared/assets/Welding_Safety31650.pdf $>$ [Accesed 26 September 2018]. 